Pomatoceros, Sabella and Amphitrite

By Joan G. Thomas. (Department of Oceanography, University of Liverpool: L.M.B.C. Memoirs on Typical British Marine Plants and Animals, 33.) Pp. vii $+88+11$ plates. (Liverpool: University Press of Liverpool ; London : Hodder and Stoughton, Ltd., 1940.) 10s. $6 d$. net.

THE Liverpool Marine Biological Committee's memoirs have proved of great service to biologists and a new volume is assured of a welcome. Vol. 33 deals with three tubicolous Polychæte worms, illustrating progressive degrees of adaptation to the sedentary habit. Amphitrite johnstoni lies hidden under rocky clefts and stones, where it makes a temporary burrow in the sand. Sabella pavonina stands upright in the mud and constructs a neat tube of selected and agglutinated mud particles lined by a smooth glistening secretion like flexible porcelain. Pomatoceros triqueter forms a rigid tube of calcareous matter, fixed to a rock and decumbent, the animal lying on its back within the tube. The last species is of importance to the general worker because it is used for artificial fertilization, its trochophore larva being easy to rear under laboratory conditions. Miss Thomas rightly makes it her main subject for investigation.

The anatomy, histology and physiology of the three worms have been described, and the author compares their adaptations to the tubicolous habit. Much of this has been well done and the figures are clear. There is, however, no drawing of a whole worm or even of a complete branchial crown, and the general reader who does not know the worms well can obtain little idea of their appearance. The account of Sabella is largely taken from Dr. Nicol's paper, and does not, unfortunately, do justice either to Sabella or to Dr. Nicol. Perhaps the very excellence of Miss Nicol's work made it difficult to find anything new, but this is no justification for mistakes in anatomy, such as occur in Fig. 30 with regard to the ciliated fæcal groove. In describing Pomatoceros Miss Thomas does not mention the obvious fact that the operculum has a conical calcareous top, and she omits this top from Fig. 5. Did she prepare this figure from a specimen fixed in an acid mixture? If so, why? A calcareous operculum is one of the generic characters of Pomatoceros. May we stress once more the importance of accuracy in anatomical detail as the fundamental requirement for physiological work ?

Living Mathematics:

a First Year College Course. By Prof. Ralph S. Underwood and Prof. Fred W. Sparks. Pp. ix +365 . (New York and London: McGraw-Hill Book Co., Inc., 1940.) $20 s$.

TTHE title of this book is a misnomer. It ought to be "Lively Mathematical Writing". Witness the following extract from the authors' treatment of the method of reductio ad absurdum: "Having hatched up a premise which collided mathematically with its conclusions, we can announce with confidence the eternal falsity of the premise and thus get a neat headlock on reality from the rear."

Stripped of such purple patches, the journalese cross-headings, and the historical references, we are left with a text-book covering in sound fashion all the work up to Intermediate B.Sc. standard-algebra, trigonometry, co-ordinate geometry, and calculus. In addition, there is a slight treatment of elementary probability and a little elementary theory of numbers. The presentation throughout reflects the experience and enthusiasm of good teachers. There is a wealth of interesting examples, which to the more staid and restrained English teacher will more than compensate for the touches of flippancy that recur throughout the text. The book is well printed on excellent paper and the diagrams finely executed, but the result is that the price is too high for the average British first-year student.

An Introduction to the Principles and Practice of Homoopathy

By Dr. Charles E. Wheeler. Second edition. Pp. viii +344. (London: William Heinemann (Medical Books), Ltd., 1940.) 15s. net.

$\mathrm{T}^{\mathrm{N}}$ the second edition of this work, of which the I first appeared twenty-one years ago, Dr. Charles E. Wheeler, consultant physician to the London Homœopathic Hospital and past president of the British Homøopathic Society, has received the collaboration of two other physicians to the hospital, Drs. J. Douglas Kenyon and Francis H. Bodman. The work is divided into two unequal parts. The first and smaller part, which contains four chapters, is devoted respectively to general considerations, the structure of the homœopathic materia medica, homœopathic pharmacy, potentization and dosage, and the choice and mode of administration of the remedy. The second part deals in alphabetical order with thirty-two of the drugs most frequently used in homœopathic medicine.

The work may be recommended as a useful handbook to all seeking information on the subject of homœopathy.

\section{Naturalist Errant}

Out with Romany Once More

By G. Bramwell Evens. Pp. vii $+168+8$ plates. (London: University of London Press, Ltd., 1940.) 5s. net.

MR. G. Bramwell Evens ('Romany' of the B.B.C.) W not only possesses the eye of the born naturalist, which makes every detail of a ramble in the country significant, but he also evidently knows, par excellence, how to pick his territory; and what is more, he knows how to impart his knowledge without incurring the danger of being considered pedagogic. As we read through the chapters of this pleasant book we are, in fact, caught up in the rambles by coppice and moor, by river and rocky dell, and, almost at first hand, we make the acquaintance of merlin, raven and buzzard, stickleback and badger, heron and woodcock, and many others, the places they live in, the food they live on. It is good, racy, direct observation, packed with interest, not lacking in its philosophy, but without sentimentality. The book is attractively illustrated by line drawings and by a number of good photographs. 